\title{
Estimation de la sensibilité variétale du pêcher à Pseudomonas syringae pv persicae sur vitroplants
}

\author{
JL Gaignard 1, F Brégeon 2, J Luisetti 1,* \\ 1 INRA, Station de pathologie végétale et phytobactériologie, Centre d'Angers, 42, rue G Morel, BP 57, 49071 Beaucouzé cedex; \\ 2 Université d'Angers, France
}

(Reçu le 2 octobre 1992; accepté le 28 décembre 1992)

\begin{abstract}
Résumé - Pseudomonas syringae pv persicae, bactérie pathogène du pêcher, a détruit plus d'un million d'arbres dans la Vallée du Rhône depuis son apparition (1966). Aucune variété n'est résistante à cette bactérie, mais un gradient de sensibilité variétale existe et les variétés se répartissent en trois classes de sensibilité. Trois années d'expérimentation au champ sont au minimum nécessaires pour déterminer le comportement de chacune des nouvelles obtentions variétales vis-à-vis de ce Pseudomonas. L'utilisation du vitroplant, pour cribler les variétés vis-à-vis de $P s \mathrm{pv}$ persicae, a donc été envisagée. Le vitroplant en croissance réagit de la même manière face à des clones bactériens d'agressivités différentes. Sur un clone d'amandier $x$ pêcher, hybride interspécifique, sensible à cette bactérie, un traitement thermique des vitroplants a permis d'obtenir des réponses différenciées après inoculation de 2 clones bactériens, l'un agressif et l'autre non agressif. II s'agit soit d'une exposition d'une heure à $-4^{\circ} \mathrm{C}$, soit d'un séjour des vitroplants à $6{ }^{\circ} \mathrm{C}$ avec une photopériode inversée (6/18 heures). Sur 3 variétés de pêcher, chacune appartenant à l'une des 3 classes de sensibilité à Ps pv persicae, le même type de traitement thermique a été appliqué après inoculation des 2 clones bactériens. Un gradient de sensibilité, conforme à celui constaté en verger, a été obtenu sur vitroplants entre les 3 variétés testées. Ce test permet de discriminer les variétés et porte-greffes très sensibles des variétés et porte-greffes peu sensibles. En revanche il est plus difficile de situer les variétés et porte-greffes de sensibilité intermédiaire. Ce test permettrait de repérer très tôt les variétés qu'il ne faut pas planter dans la région concernée par la maladie. Le vitroplant pourrait être également utilisé pour mesurer l'agressivité des souches.
\end{abstract}

Pseudomonas syringae pv persicae $=$ pêcher $/$ sensibilité variétale $/$ pouvoir pathogène $/$ vitroplant

Summary - Monitoring the susceptibility of peach cultivars to Pseudomonas syringae pv persicae using in vitro plants. Pseudomonas syringae pv persicae, causal agent of a bacterial dieback has destroyed more than 1 million peach in the Rhone Valley since it occurred for the first time in 1966. There is no resistant variety and all the cultivated varieties are distributed in 3 classes of susceptibility according to the results of a 3-yr field trial. Carrying out inoculation tests on in vitro plants has been considered. Experiments were performed with either a hybrid almond $x$ peach line or with 3 peach varieties corresponding to each previously defined susceptibility class. Two bacterial clones differing in aggressiveness were used for inoculation. The inoculation of rapidly growing almond $x$ peach in vitro plants did not lead to any significant differentiation of the 2 bacterial clones. When treated by exposure either to negative temperature $\left(-4{ }^{\circ} \mathrm{C}\right)$ for $1 \mathrm{hr}$ or to low temperature $\left(6^{\circ} \mathrm{C}\right)$ for the duration of the experiment in addition with an inverted photoperiod (6/18) the in vitro plants reacted according to the aggressiveness of the inoculated clones. Moreover, the 3 peach varieties demonstrated a differential susceptibility to the bacterial clones similar to that observed in field. The test which has been developed on in vitro plants appeared to be useful in differentiating varieties with high susceptibility from those with low susceptibility but not accurate enough for varieties with intermediate susceptibility. It could be used as a preliminary test, either to discard the most susceptible varieties before introduction into orchard or before the field trial. It could also be performed to determine the aggressiveness of strains.

Pseudomonas syringae $p v$ persicae / peach / susceptibility / pathogenicity / in vitro plant 


\section{INTRODUCTION}

Une maladie bactérienne nouvelle et particulièrement grave a été signalée en France (vallée du Rhône) en 1966 (Vigouroux, 1968, 1970). Elle a détruit plus d'un million d'arbres en 25 ans. La bactérie responsable est $P$ seudomonas syringae pv persicae ( $P S \mathrm{pv}$ persicae) (Prunier et al, 1970).

Cette bactérie se caractérise par une phase épiphyte pendant la période végétative (Gardan et al, 1972). L'infection se développe essentiellement durant la période de repos hivernal (Prunier et al, 1973). La réussite de l'infection est fonction de la qualité et de la quantité de l'inoculum (Luisetti et al, 1973; Luisetti, 1983), du niveau de sensibilité de la plante au moment de la pénétration (Gardan et al, 1971; Prunier et al, 1973 ) et des conditions d'environnement (Vigouroux, 1979; Vigouroux et Huguet, 1980; Vigouroux et al, 1987).

Les méthodes de lutte et les techniques culturales proposées jusqu'à présent permettent de limiter l'extension de la maladie mais restent insuffisantes (Luisetti et al, 1992). Aucune variété n'est résistante (Luisetti et al, 1992). Parmi la gamme de variétés cultivées on constate cependant un large gradient de sensibilité (Gardan et al, 1971; Luisetti et al, 1984, 1992) et les variétés peuvent être réparties en 3 classes de sensibilité. Les arbres de variétés très sensibles ont une forte probabilité de mort rapide. Les arbres de variétés peu sensibles ou tolérantes peuvent développer quelques symptômes qui restent, en règle générale, peu graves et sans conséquence significative. Les arbres de variétés moyennement sensibles, de comportement intermédiaire, peuvent être parfois sévèrement touchés. Une lutte efficace contre cette maladie implique nécessairement l'implantation de variétés peu sensibles. La connaissance du comportement du matériel vétégal vis-à-vis de $P s$ pv persicae est donc un objectif essentiel chez cette espèce fruitière où existe un constant renouvellement variétal. C'est aussi un préalable à tout programme de création de variétés résistantes.

Trois années d'expérimentation en plein champ sont nécessaires pour connaître la sensibilité de pêchers à cette bactérie (Gardan et al, 1971). C'est long mais c'est un préalable indispensable à la mise sur le marché d'une nouvelle obtention variétale. Comme cela a été fait antérieurement sur plusieurs modèles conduits in vitro : agrumes - Xanthomonas campestris pv citri (Lopez et Navarro, 1981) et poirier - Erwinia amylovora (Brisset et al, 1988), l'utilisation du vitroplant de pêcher a été envisagée pour réaliser un premier criblage de sensibilité des variétés de pêcher à $P s$ pv persicae.

La culture in vitro des Prunus, en particulier la micropropagation du pêcher et de ses portegreffes, est maintenant maîtrisée (Boxus et Quoirin, 1974; Carré et al, 1979; Zuccherelli, 1979; Navatel, 1980). La multiplication végétative in vitro des porte-greffes difficiles à multiplier par les techniques classiques, en particulier de l'amandier x pêcher (INRA GF 677), est actuellement généralisée par microbouturage (Martin, 1980; Navatel, 1982).

Par ailleurs, au cours de recherches antérieures, Luisetti (1983) a sélectionné, à partir d'une souche agressive de $P s \mathrm{pv}$ persicae, des clones agressifs et non agressifs sur la base de leur capacité à produire ou non une toxine. Nous avons utilisé ce matériel microbiologique de pouvoir pathogène différencié pour étudier la réponse des vitroplants d'amandier $x$ pêcher et de pêcher à l'inoculation de cette bactérie et pour mettre en place un test de sensibilité bactérienne sur ce matériel végétal. Les conditions de culture appliquées aux vitroplants ont été modulées afin d'obtenir des réponses rapides et reproductibles mais surtout différenciées selon la sensibilité variétale et l'agressivité de la souche utilisée.

\section{MATÉRIEL ET MÉTHODES}

\section{Matériel végétal}

Les travaux ont été menés sur 2 types de matériel :

- des vitroplants d'un hybride interspécifique naturel, l'amandier x pêcher, clone INRA GF 677; le clone in vitro nous a été fourni par le laboratoire de recherche de physiologie végétale d'Angers; c'est un hybride de première génération, utilisé comme porte-greffe, d'une grande vigueur et très bien adapté aux terrains calcaires irrigables. II est multiplié par voie végétative (Navatel, 1982). II s'est révélé très sensible à $P s$ pv persicae (Gardan et al, 1971) et donc intéressant pour notre étude;

- des vitroplants de 3 variétés de pêcher de sensibilité à $P$ s pv persicae parfaitement connue : Redwing (très sensible), July Lady (moyennement sensible) et Redskin (peu sensible). Ces trois variétés ont été clonées selon la méthode suivante : les explants ont été prélevés à partir de rameaux cueillis durant une période de croissance des tiges; après désinfection, des segments de tige de $2 \mathrm{~cm}$ comportant un bourgeon, sont 
mis en culture sur le milieu (mg.t-1) $\mathrm{KNO}_{3}, 1800$; $\mathrm{NH}_{4} \mathrm{NO}_{3}, 400 ; \mathrm{MgSO}_{4}, 7 \mathrm{H}_{2} \mathrm{O}, 360 ; \mathrm{Ca}\left(\mathrm{NO}_{3}\right)^{2}, 4 \mathrm{H}_{2} \mathrm{O}$, 1200; $\mathrm{KH}_{2} \mathrm{PO}_{4}, 270 ; \mathrm{Na}_{2} \mathrm{EDTA}, 37,3 ; \mathrm{FeSO}_{4}, 7 \mathrm{H}_{2} \mathrm{O}$, 27,8; $\mathrm{MnSO}_{4}, 4 \mathrm{H}_{2} \mathrm{O}, 1 ; \mathrm{ZnSO}_{4}, 8,6 ; \mathrm{H} 3 \mathrm{BO} 3,6,2 ; \mathrm{KI}$ 0,$08 ; \mathrm{Na}_{2} \mathrm{MoO}_{4}, 2 \mathrm{H}_{2} \mathrm{O}, 0,25 ; \mathrm{CoCl}_{2}, 6 \mathrm{H}_{2} \mathrm{O}, 0,025$; $\mathrm{CuSO}_{4}, 5 \mathrm{H}_{2} \mathrm{O}, 0,025$; Biotine, 0,1; Thiamine $\mathrm{HCl}, 1$; $\mathrm{Ac}$ nicotinique, 1; Pyridoxine $\mathrm{HCl}, 1$; méso-inositol, 100; Glycine, 5; BAP, 0,4; AIB, 0,15; GA3, 0,10; Glucose, 30 000, Agar Agar, 6000 .

Les microboutures obtenues sont ensuite multipliées sur le même milieu, modifié au niveau des teneurs en Glycine $(0,75)$, en $\operatorname{BAP}(0,75)$, en AIB $(0,25)$ et en GA3 $(0,25)$. A partir des touffes composées de 6 à 8 plantules de 0,5 à $2 \mathrm{~cm}$ de hauteur, chaque explant individualisé est mis dans un tube contenant $15 \mathrm{ml}$ de milieu gélosé pour l'amandier $x$ pêcher et $12 \mathrm{ml}$ de milieu liquide avec support synthétique Milcap $^{\circledR}$ (Challet Hérault, Nuaillé 49 ) pour le pêcher. Le repiquage est réalisé en atmosphère stérile, sous une hotte à flux laminaire. Le milieu PAM (en mg. $\mathrm{I}^{-1}$ : $\mathrm{NH}_{4} \mathrm{NO}_{3}, 1650 ; \mathrm{KNO}_{3}, 1900 ; \mathrm{CaCl}_{2}, 2 \mathrm{H}_{2} \mathrm{HO}, 440$; $\mathrm{MgSO}_{4}, 7 \mathrm{H}_{2} \mathrm{O}, 370 ; \mathrm{KH}_{2} \mathrm{PO}_{4}, 170 ; \mathrm{ZnSO}_{4}, 7 \mathrm{H}_{2} \mathrm{O}, 8,6$; $\mathrm{H}_{3} \mathrm{BO}_{3}, 6,2 ; \mathrm{MnSO}_{4}, 4 \mathrm{H}_{2} \mathrm{O}, 22,3 ; \mathrm{Na}_{2} \mathrm{MoO}_{4}, 4 \mathrm{H}_{2} \mathrm{O}$, 0,$25 ; \mathrm{Kl}, 0,83 ; \mathrm{CuSO}_{4}, 5 \mathrm{H}_{2} \mathrm{O}, 0,025 ; \mathrm{CoCl}_{2}, 6 \mathrm{H}_{2} \mathrm{O}$, 0,$025 ; \mathrm{FeSO}_{4}, 7 \mathrm{H}_{2} \mathrm{O}, 27,8 ; \mathrm{Na}_{2} \mathrm{EDTA}, 2 \mathrm{H}_{2} \mathrm{O}, 37,3$; thiamine $\mathrm{HCl}, 0,4$; méso-inositol, $100 ; \mathrm{GA}_{3}, 0,1$; $\mathrm{BAP}$, 1; AIB, 0,1; saccharose, 30000; agar agar, 7 000) pour l'amandier $x$ pêcher et le milieu Murashige et Skoog (1962) modifié pour les teneurs en BAP $(0,08)$ et AIB
$(0,02)$ et la nature de la gibbérelline $\left(G A_{4}+G A 7,4\right)$ pour le pêcher, sont utilisés. Un séjour des vitroplants d'amandier $x$ pêcher à $4{ }^{\circ} \mathrm{C}$ pendant quelques $\mathrm{j}$ ou un séjour prolongé sur un même milieu favorise l'allongement. Pour les vitroplants de pêcher, la combinaison d'acide gibbérellique et le support Milcap ${ }^{\circledR}$ favorisent l'allongement. II a été nécessaire de sélectionner des vitroplants d'une taille $\geq 2 \mathrm{~cm}$ pour l'amandier $x$ pêcher afin de pouvoir apprécier le développement de la nécrose. Les pêchers ont une taille de $5-8 \mathrm{~cm}$. Pour l'amandier $x$ pêcher, conduit sur milieu gélosé, seuls les vitroplants dont les racines ne sont pas ou peu développées sont utilisés, afin d'éviter la formation de lésions mécaniques à leur niveau, au moment de l'inoculation, le vitroplant étant retiré du tube quelques instants. Ces 2 contraintes ont pour effet de limiter le nombre de vitroplants disponibles pour chaque expérimentation et de réduire les dispositifs expérimentaux. En revanche, pour le pêcher, l'utilisation du support synthétique évite de provoquer des lésions, l'ensemble vitroplant et support étant retiré pour l'inoculation.

Avant l'inoculation, les vitroplants sont élevés en cellule de vitroculture sous thermopériode de $24 \%$ $19^{\circ} \mathrm{C}$ et photopériode de $16 / 8 \mathrm{~h}$. L'intensité lumineuse est de 3000 lux. Les traitements thermiques et les conditions d'incubation après l'inoculation sont indiqués dans le tableau $\mathrm{I}$.

Tableau I. Conduite des vitroplants et observation des symptômes sur amandier x pêcher INRA GF 677 et sur pêcher (3 variétés).

\begin{tabular}{|c|c|c|c|c|c|c|}
\hline \multirow{2}{*}{$\begin{array}{l}\text { Essai } \\
1\end{array}$} & \multirow{2}{*}{$\begin{array}{l}\text { Milieu/Traitements } \\
\text { des vitroplants après inoc } \\
\text { Photopériode }\end{array}$} & \multicolumn{3}{|c|}{ Premiers symptômes } & \multicolumn{2}{|c|}{ Symptômes à $30 j$} \\
\hline & & $\mathrm{GF}^{\mathrm{b}}$ & $8 \mathrm{j}$ & $30 \mathrm{j}$ & Léger brunissem & \\
\hline 2 & $\begin{array}{l}\text { PAM depuis } 20 \text { semaines } \\
24^{\circ} / 19^{\circ} \mathrm{C}, 16 / 8 \mathrm{~h}\end{array}$ & GF : & $8 \mathrm{j}$ & $\mathrm{NAC}$ & $\begin{array}{l}\text { Nécrose autour } \\
\text { de la blessure }\end{array}$ & Pas de symptôme \\
\hline 3 & $\begin{array}{l}\text { PAM depuis } 12 \text { semaines } \\
\text { Séjour à }-4^{\circ} \mathrm{C}, 4 \text { jours après } \\
\text { puis } 24^{\circ} / 19^{\circ} \mathrm{C}, 16 / 8 \mathrm{~h}\end{array}$ & GF : & $8 \mathrm{j}$ & $15 j$ & $\begin{array}{l}\text { Nécrose totale } \\
\text { du vitroplant }\end{array}$ & Nécrose $5 \mathrm{~mm}$ \\
\hline 4 & $\begin{array}{l}\text { PAM depuis } 12 \text { semaines } \\
6^{\circ} \mathrm{C}, 8 / 16 \mathrm{~h}\end{array}$ & GF : & $9 \mathrm{j}$ & $30 \mathrm{j}$ & Nécrose $2,5 \mathrm{~mm}$ & Léger brunissement \\
\hline 5 & $\begin{array}{l}\text { MS modifiéd depuis } 3 \text { semaines } \\
6^{\circ} \mathrm{C}, 16 / 8 \mathrm{~h}\end{array}$ & $\begin{array}{l}\text { RW' }: \\
J^{\mathrm{b}}: \\
\mathrm{RK} K^{\mathrm{b}}:\end{array}$ & $\begin{array}{l}22 \mathrm{j} \\
22 \mathrm{j} \\
22 \mathrm{j}\end{array}$ & $\begin{array}{l}22 \mathrm{j} \\
30 \mathrm{j} \\
30 \mathrm{j}\end{array}$ & Nécrose partielle & tale du vitroplante \\
\hline 6 & $\begin{array}{l}\text { MS modifié depuis } 3 \text { semaines } \\
\text { séjour à }-3^{\circ} \mathrm{C}, 4 \text { jours après } \\
\text { inoulation, } 6^{\circ} \mathrm{C}, 16 / 8 \mathrm{~h}\end{array}$ & $\begin{array}{l}\text { RW: } \\
\text { JL: } \\
\text { RK : }\end{array}$ & $\begin{array}{l}15 j \\
22 j \\
22 j\end{array}$ & $\begin{array}{l}22 \mathrm{j} \\
30 \mathrm{j} \\
\mathrm{NA}\end{array}$ & Nécrose partielle & tale du vitroplant ${ }^{\ominus}$ \\
\hline
\end{tabular}

\footnotetext{
a PAM : milieu amandier x pêcher; ${ }^{b}$ GF : GF 677; RW : Redwing; JL : July Lady; RK : Redskin; ${ }^{c}$ NA : symptôme non apparu; ${ }^{d}$ MS modifié : milieu pê$\mathrm{cher}^{e} \mathrm{Ce}$ sont les fréquences de vitroplants plus ou moins nécrosés qui différencient les clones et les variétés (fig 2).
} 


\section{Matériel microbiologique}

Deux espèces bactériennes phytopathogènes ( $P s \mathrm{pv}$ persicae et $P s$ pv syringae) et 2 espèces bactériennes saprophytes (Erwinia herbicola et Pseudomonas fluorescens) sont inoculées en comparaison, au cours d'un essai préliminaire.

Par la suite, toutes les inoculations sont réalisées avec 2 clones bactériens, l'un toxinogène et agressif (235), l'autre atoxinogène et non agressif (239), obtenus, selon la méthode décrite par Luisetti (1983), à partir d'une culture de la souche de $P s$ pv persicae INRA M $24 \mathrm{Sm}^{r}$, mutant spontané sélectionné pour la résistance à la streptomycine; il a été montré chez $P S$ $\mathrm{pv}$ persicae une relation étroite entre toxinogenèse et agressivité (Luisetti, 1983). Ces clones sont conservés par congélation dans de l'eau distillée stérile, à raison de $1 \mathrm{ml}$ par cryotube. Au moment de l'utilisation, les bactéries sont décongelées et ensemencées sur milieu LPGA (en g..$^{-1}$ : Extrait de levure, 8; biogélytone, 8; glucose, 7; agar agar, 15; $\mathrm{pH} 7$ ) additionné de streptomycine (50 mg. l-1 $^{-1}$ Sygma). Les boîtes de Petri sont mises en incubation à $16{ }^{\circ} \mathrm{C}$ durant $60 \mathrm{~h}$.

\section{Méthodes}

La bactérie pénétrant dans les tissus du pêcher par l'intermédiaire soit de blessures (plaies de taille), soit des plaies pétiolaires (Prunier et al, 1970), c'est la première voie de pénétration qui a été utilisée sur vitroplant. La blessure est obtenue par une incision de la tige faite à l'aide d'un scalpel. Pour dégager la blessure et faciliter le dépôt d'inoculum, quelques feuilles sont éliminées autour de l'incision. II est nécessaire d'être vigilant lors du dépôt de l'inoculum sur la blessure afin de ne pas infecter les plaies au niveau des pétioles coupés. Pour réaliser cette opération, le vitroplant doit être retiré du tube durant une trentaine de secondes. Ce travail est accompli stérilement, sous une hotte à flux laminaire. Le vitroplant inoculé est ensuite réintroduit dans son tube. L'inoculation des vitroplants est réalisée à partir d'une suspension dosée à $1-5 \times 10^{8}$ bactéries par $\mathrm{ml}$ et préparée dans de l'eau distillée stérile. Vingt microlitres de suspension bactérienne sont déposés, à l'aide d'une micropipette, sur chaque blessure, ce qui introduit de 3 à $5 \times 10^{6}$ germes par blessure (estimation réalisée dans les $2 \mathrm{~h}$ suivant l'inoculation). Au cours de l'essai préliminaire, réalisé sur l'hybride amandier x pêcher, en plus des vitroplants inoculés avec chacune des 4 souches, des vitroplants témoins, maintenus sur le même milieu depuis 4 semaines, ont été blessés selon la même méthode et une microgoutte d'eau distillée stérile a été déposée sur les blessures.

Le premier essai est réalisé sur des vitroplants d'amandier $x$ pêcher récemment repiqués (depuis 2 semaines) sur milieu PAM. Pour les essais suivants réalisés sur amandier $x$ pêcher, une modification de l'état physiologique du vitroplant est recherchée pour tenir compte de la caractéristique de la maladie qui se développe essentiellement pendant le repos végétatif de l'arbre (Vigouroux, 1970; Prunier et al, 1973). On a d'abord cherché à limiter la nutrition du vitroplant en le maintenant sur le même milieu durant une longue période (20 semaines). Puis on a associé à ce type de traitement (12 semaines sur le même milieu) soit un choc thermique $\left(1 \mathrm{~h}\right.$ à $\left.-4{ }^{\circ} \mathrm{C}\right)$ appliqué $4 \mathrm{j}$ après l'inoculation, soit une incubation à une température froide $\left(6^{\circ} \mathrm{C}\right)$ sous une photopériode inversée $(6 / 18 \mathrm{~h})$.

Dans le cas des 3 variétés de pêcher, la méthodologie est légèrement modifiée. Les vitroplants, maintenus sur le même milieu pendant 3 à 4 semaines, sont placés pendant $4 \mathrm{j}$ après l'inoculation, sous une thermopériode de $24 / 19^{\circ} \mathrm{C}$ et une photopériode $16 / 8 \mathrm{~h}$; par la suite, ils sont transférés à une température de $6{ }^{\circ} \mathrm{C}$. Dans une seconde expérience, un choc thermique $\left(-3^{\circ} \mathrm{C}\right.$ pendant $\left.1 \mathrm{~h}\right)$, placé avant le transfert à la température de $6^{\circ} \mathrm{C}$, est introduit dans la séquence des traitements. Le choc thermique est obtenu dans une chambre froide dans laquelle on a provoqué un gel artificiel de type convectif tel que l'ont décrit Flura et al (1991); l'abaissement de la température est linéaire, de l'ordre de $2{ }^{\circ} \mathrm{C} / \mathrm{h}$, avec un plateau d' $1 \mathrm{~h}$ à la température retenue $\left(-4^{\circ} \mathrm{C}\right.$ pour l'amandier $\mathrm{x}$ pêcher et $-3^{\circ} \mathrm{C}$ pour le pêcher); la température remonte ensuite à raison de $5{ }^{\circ} \mathrm{C} / \mathrm{h}$.

Pour chacun des 2 clones bactériens (235 et 239), le nombre de vitroplants à inoculer est déterminé de manière à ce qu'à chaque contrôle des populations, 8 vitroplants puissent être analysés.

\section{Observations et analyses}

Les vitroplants sont régulièrement observés pendant une période de $30 \mathrm{j}$ après inoculation et les symptômes sont décrits. La fréquence des contrôles est variable pour les vitroplants d'amandier $x$ pêcher selon les essais; les nécroses sur tiges sont mesurées individuellement.

Pour le pêcher et pour les 2 essais, les observations sont faites $1,4,8,15,22$ et 30 j après l'inoculation. Les notations au $30^{\mathrm{e}} \mathrm{j}$ sont basées sur une répartition des dégâts en 3 classes : (0) pas de symptôme, (1) nécrose limitée autour de la blessure d'inoculation (type 1), (2) nécrose étendue entraînant le dessèchement de la tige (type 2).

A chaque examen, la population bactérienne présente dans les tissus est estimée : chacun des 8 vitroplants est broyé séparément pendant $10 \mathrm{~s}$, sous conditions aseptiques et dans $5 \mathrm{ml}$ d'eau distillée stérile à l'aide d'un broyeur homogénéiseur UltraTurrax ${ }^{(\mathbb{B}}$. Une aliquote de ce broyat $(50 \mu l)$ et de chacune des 3 premières dilutions est ensuite étalée sur plaque gélosée de milieu LPGA dans lequel on a incorporé un fongicide à raison de $50 \mathrm{mg} . \mathrm{I}^{-1}$ (cycloheximide, Sygma) et de la streptomycine à raison de $50 \mathrm{mg} . \mathrm{I}^{-1}$ (Sygma); 3 boîtes par dilution sont ensemencées, elles sont mises en incubation à $16^{\circ} \mathrm{C}$ pendant $60 \mathrm{~h}$. 
L'activité toxinogène des clones est vérifiée avant inoculation au travers de la mise en évidence de l'inhibition de la croissance in vitro d'une souche de $\mathrm{Ba}$ cillus sp (souche INRA B6). Pour chaque clone bactérien, 64-96 colonies sont prélevées au hasard sur les boîtes de Petri qui ont servi au dénombrement, et déposée individuellement sur une plaque gélosée de milieu LPGA, préalablement ensemencée par une nappe de Bacillus sp. Après 48 heures d'incubation à $16^{\circ} \mathrm{C}$, on note la présence d'une zone d'inhibition de croissance du Bacillus sp autour de chaque isolat de $P$ s pv persicae (Luisetti, 1983).

\section{RÉSULTATS}

\section{Réponse de l'amandier $x$ pêcher à l'inoculation de bactéries phytopathogènes ou saprophytes}

Seuls les vitroplants inoculés avec des espèces phytopathogènes, $P s \mathrm{pv}$ syringae ou $P s \mathrm{pv}$ persicae, présentent des nécroses autour de la blessure alors que les vitroplants inoculés avec de l'eau stérile ou avec une espèce saprophyte, $P$ fluorescens ou $E$ herbicola, ne montrent aucun symptôme.

\section{Réponse de l'amandier $x$ pêcher à l'inoculation de $\mathrm{P} s \mathrm{pv}$ persicae}

\section{Vitroplants en croissance (essai 1)}

Les symptômes obtenus restent limités à de légers brunissements qui apparaissent autour des blessures; ces manifestations sont visibles plus tôt sur les vitroplants inoculés avec le clone 235 (tableau I).

La dynamique des populations in vitro est identique pour les 2 clones : elle est caractérisée par une chute dès le 1 er jour d'incubation, puis par une augmentation rapide au cours des 7 jours suivants, permettant d'atteindre une teneur en bactéries supérieure à $10^{6}$ par plant; par la suite la croissance reste plus limitée (fig 1).

\section{Vitroplants sur milieu en cours d'épuisement (essai 2)}

Huit jours après l'inoculation, les premiers brunissements apparaissent, autour des blessures sur les tiges inoculées avec le clone 235. Par la suite, les brunissements évoluent en nécroses; la partie apicale de la tige se dessèche alors. En revanche, aucun symptôme n'apparaît sur les plants inoculés avec le clone 239 (tableau I).

Cette différence de comportement des 2 clones bactériens se manifeste aussi au niveau de la dynamique des populations in vivo. Après une baisse, intervenant le premier jour et commune aux 2 clones, la population du clone 235 augmente rapidement pour atteindre au $8^{\mathrm{e}} \mathrm{j}$ un niveau $>10^{6}$ bactéries/plant; cette croissance se poursuit encore par la suite mais à un taux nettement plus faible; en revanche pour le clone 239 , à une phase de croissance limitée qui permet à peine de dépasser $10^{3}$ bactéries/plant succède une phase de régression de la population qui, après $30 \mathrm{j}$ d'incubation compte moins de $10^{2}$ cellules par vitroplant (fig 1 ).

\section{Vitroplants sur milieu en cours d'épuisement et subissant un choc thermique (essai 3)}

Au cours du choc thermique à $-2{ }^{\circ} \mathrm{C}$, subi par les vitroplants $4 \mathrm{j}$ après inoculation, il n'y a pas de prise en glace dans les tissus car $P s$ pv persicae n'est apte à provoquer la rupture de surfusion qu'à partir de $-5{ }^{\circ} \mathrm{C}$ (Paulin et Luisetti, 1978). Une nécrose de la tige est visible après 8 j (clone 235) ou 15 j (clone 239) d'incubation. Par la suite, le clone 235 entraine la nécrose totale de la tige de plusieurs vitroplants alors que le clone 239 provoque une nécrose limitée à $5 \mathrm{~mm}$ en moyenne autour de la blessure, mais cependant, au-dessus de la nécrose les feuilles jaunissent et se dessèchent. A $30 \mathrm{j}$, l'intensité des symptômes est plus importante que lors des essais précédents et la différence entre les 2 clones bactériens est bien marquée. En particulier, les feuilles de vitroplants inoculés avec le clone 235 présentent des taches nombreuses dont l'origine est bactérienne comme le confirme l'isolement, alors que ce phénomène n'est pas observé sur les feuilles des vitroplants inoculés avec le clone 239 (tableau I).

L'analyse de la dynamique des populations in vivo des 2 clones confirme la différence de comportement; en effet, si l'évolution générale est la même, caractérisée par une succession de 3 phases : baisse des populations, croissance accélérée puis stabilisation; un écart significatif d'une unité logarithmique est constaté en faveur du clone 235 entre les niveaux des populations à l'issue de l'essai (fig 1). 
Vitroplants sur milieu en cours d'épuisement et soumis à une température basse et une photopériode inversée (essai 4)

Une évolution différente des symptômes est observée selon le clone bactérien inoculé. Pour le clone 235, un brunissement des tissus apparaît autour de la blessure dès le ge $\mathrm{j}$ et après $30 \mathrm{j}$, la nécrose atteint $2,5 \mathrm{~mm}$ en moyenne. Pour le clone 239, les symptômes ne sont visibles qu'à $30 \mathrm{j}$ et restent limités à un simple brunissement autour de la blessure (tableau I).

Les 3 phases précédemment décrites de la dynamique des populations in vivo sont toujours observées; la baisse initiale reste limitée mais cependant plus marquée pour le clone 239; par la suite, l'écart de niveau entre les clones s'estompe progressivement (fig 1).

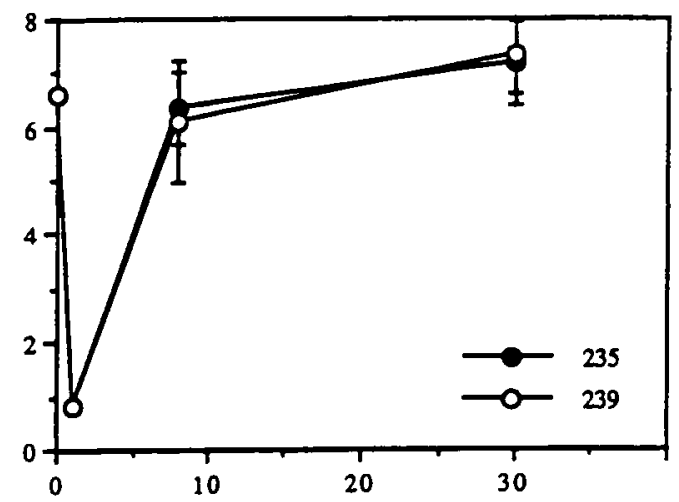

I : intervalle de confiance

Essai 1 - Vitroplants en croissance, $24^{\circ} / 19^{\circ} \mathrm{C}, 16 / 8 \mathrm{~h}$

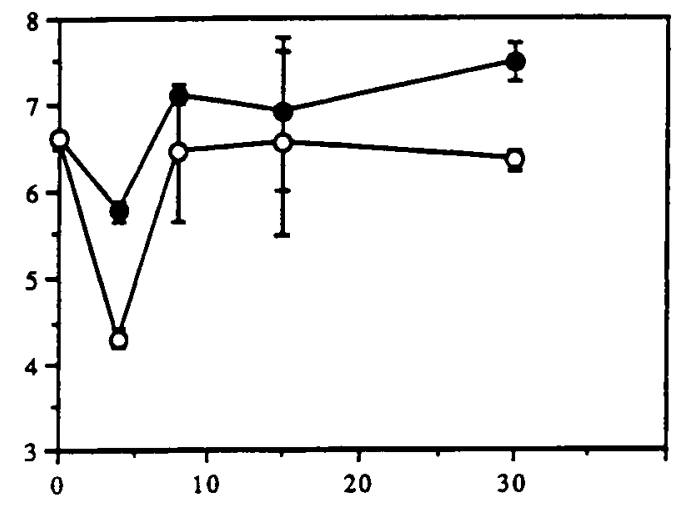

Essai 3 - Vitroplants sur milieu en cours d'épuisement et subissant un choc thermique $\left(-4^{\circ} \mathrm{C}\right.$ durant 1 heure) et séjour à $24^{\circ} / 19^{\circ} \mathrm{C}, 16 / 8 \mathrm{~h}$

\section{Réponse du pêcher à l'inoculation de $\mathrm{P} s \mathrm{pv}$ persicae}

\section{Vitroplants des variétés Redwing, July Lady et Redskin soumis à une température basse (essai 5)}

Dans les conditions spécifiques de cet essai, les premiers symptômes n'apparaissent sur les 3 variétés qu'après 22 j d'incubation. Pour le clone bactérien 235 , on observe alors $25 \%$ de nécroses de type 1 sur la variété Redwing, $13 \%$ sur la variété July Lady et $13 \%$ sur la variété Redskin; en revanche, le clone bactérien 239 ne provoque que des nécroses limitées et sur une faible fraction $(6 \%)$ des vitroplants de la variété Redwing. A l'issue de l'essai (30 j) on observe entre les 2 clones bactériens inoculés et entre

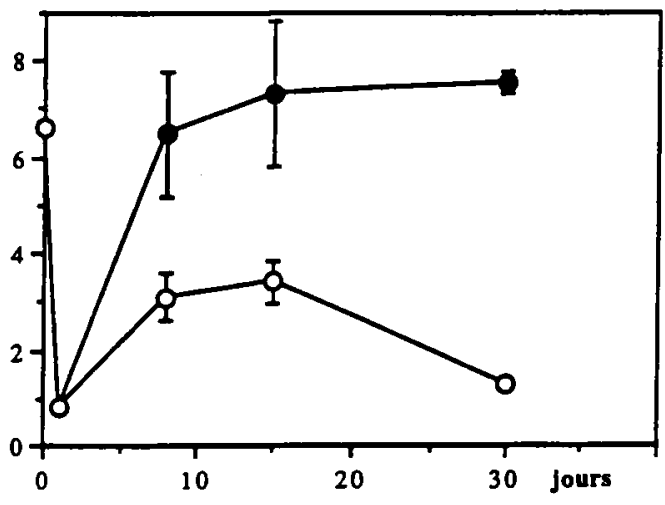

Essai 2 - Vitroplants sur milieu en cours d'épuisement, $24^{\circ} / 19^{\circ} \mathrm{C}, 16 / 8 \mathrm{~h}$

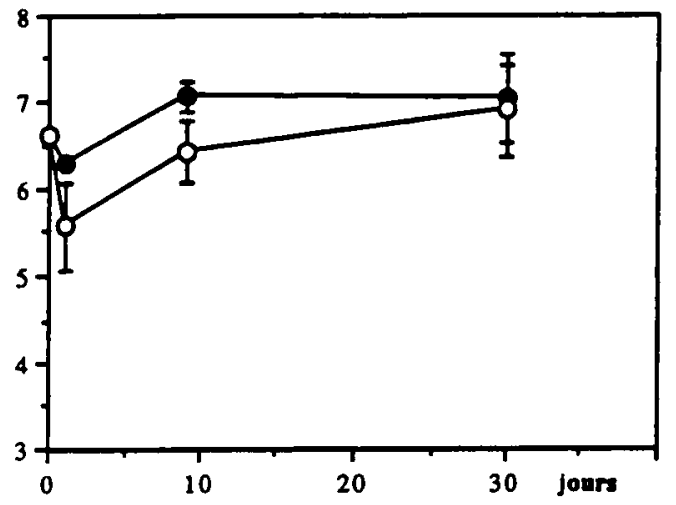

Essai 4 Vitroplants sur milieu en cours d'épuisement et soumis à une température basse $\left(6^{\circ} \mathrm{C}\right)$ et à une photopériode inversée $(8 / 16 \mathrm{~h})$

Fig 1. Dynamique des 2 clones de $P s$ pv persicae sur vitroplants d'amandier x pêcher INRA GF 677 en fonction des conditions expérimentales. 
les 3 variétés de sensibilité différente, un net gradient des dégâts (fig 2). La variété Redwing est très touchée, $75 \%$ des vitroplants inoculés avec le clone 235 présentant des nécroses, dont $25 \%$ de type 2 avec dessèchement de la tige; en revanche, seulement $33 \%$ des vitroplants de la variété Redskin montrent des nécroses qui restent limitées (type 1).

La différence d'agressivité des 2 clones est confirmée : $48 \%$ des vitroplants, toutes variétés confondues, inoculées avec le clone 235 et seulement $22 \%$ de ceux inoculés avec le clone 239 expriment des symptômes.

Dans les conditions de cet essai, la dynamique des populations ne semble être influencée ni par l'agressivité du clone inoculé ni par la variété support. La dynamique des 2 clones bactériens dans les tissus est du même type pour les 3 variétés. La multiplication est importante puisqu'elle atteint et se stabilise, au $15^{\mathrm{e}}$ jour, à une moyenne de $10^{9}$ bactéries par plant (fig 3 ).

\section{Vitroplants des variétés Redwing, July Lady et Redskin soumis à une température basse et à un choc thermique (essai 6)}

Quinze jours après l'inoculation, les premiers symptômes sont visibles sur $12,5 \%$ des vitroplants de la variété Redwing. Au $22^{\mathrm{e}} \mathrm{j}$, des différences entre les 3 variétés et les 2 clones bactériens sont observées : dans le cas d'inoculation avec le clone $235,46 \%$ des vitroplants de la variété Redwing présentent des nécroses, à la fois de type 1 et de type 2 et $15 \%$ des vitroplants de la variété July Lady ou Redskin, des nécroses de type 1; le clone 239 n'a entraîné des nécroses, li-

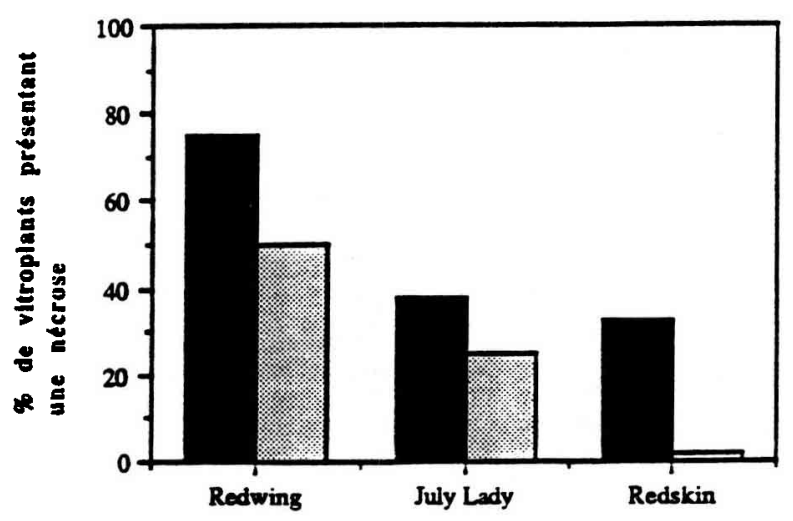

Essai 5 : Vitroplants soumis à une température basse $\left(6^{\circ} \mathrm{C}\right)$ et à une photopériode inversée $(8 / 16$ h) mitées, que sur $25 \%$ des vitroplants de la variété Redwing. A l'issue de l'essai, le gradient de sensibilité variétale est confirmée, la fréquence de vitroplants nécrosés passant de $87 \%$ pour la variété Redwing, à $43 \%$ pour la variété July Lady, et à $29 \%$ pour la variété Redskin (inoculation avec le clone 235); on retrouve aussi la différence d'agressivité entre les clones : $53 \%$ et $26 \%$ de vitroplants sont nécrosés lorsqu'inoculés respectivement avec 235 et 239 (toutes variétés confondues) (fig 2).

\section{DISCUSSION}

Le premier essai a permis de confirmer que seules des bactéries phytopathogènes ( $P s \mathrm{pv}$ syringae et $P$ s pv persicae) peuvent engendrer des lésions sur vitroplants de l'hybride interspécifique amandier $x$ pêcher. Ce premier résultat était essentiel pour la poursuite des travaux sur ce matériel végétal.

Les essais suivants permettent de distinguer 3 types de réponses du vitroplant d'amandier $\mathrm{x}$ pêcher inoculé avec $P s$ pv persicae (comparaison d'un clone agressif 235 et d'un clone non agressif 239) en fonction des conditions de milieu et d'environnement :

- le vitroplant sur milieu riche (installé sur milieu PAM depuis 4 semaines ou moins), donne une réponse non différenciée selon le clone bactérien inoculé; les symptômes sont limités à de légers brunissements sur tige autour de la blessure, malgré une multiplication intense des bactéries; l'absence de symptômes sur vitroplants d'amandier x pêcher maintenus sur milieu

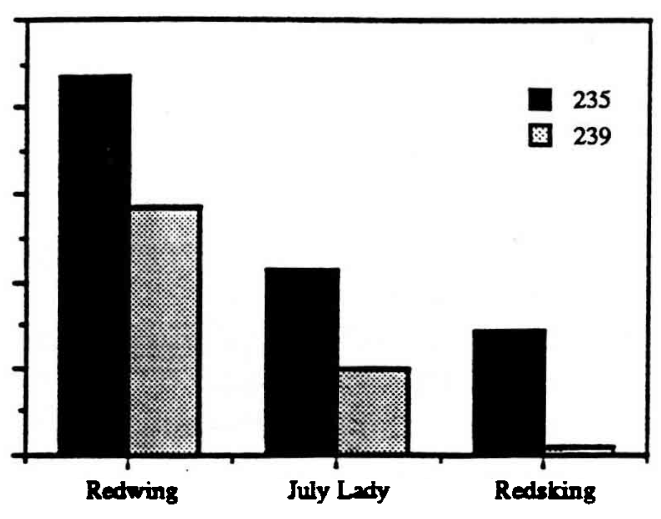

Essai 6 : Vitroplants soumis à une température basse $\left(6^{\circ} \mathrm{C}\right)$, à une photopériode inversée $(8 / 16 \mathrm{~h})$ et à un choc thermique $\left(-3^{\circ} \mathrm{C}\right.$ durant 1 heure)

Fig 2. Distribution des dégâts sur vitroplants de pêcher après 30 jours, en fonction de la variété, du clone bactérien inoculé et des conditions expérimentales. 

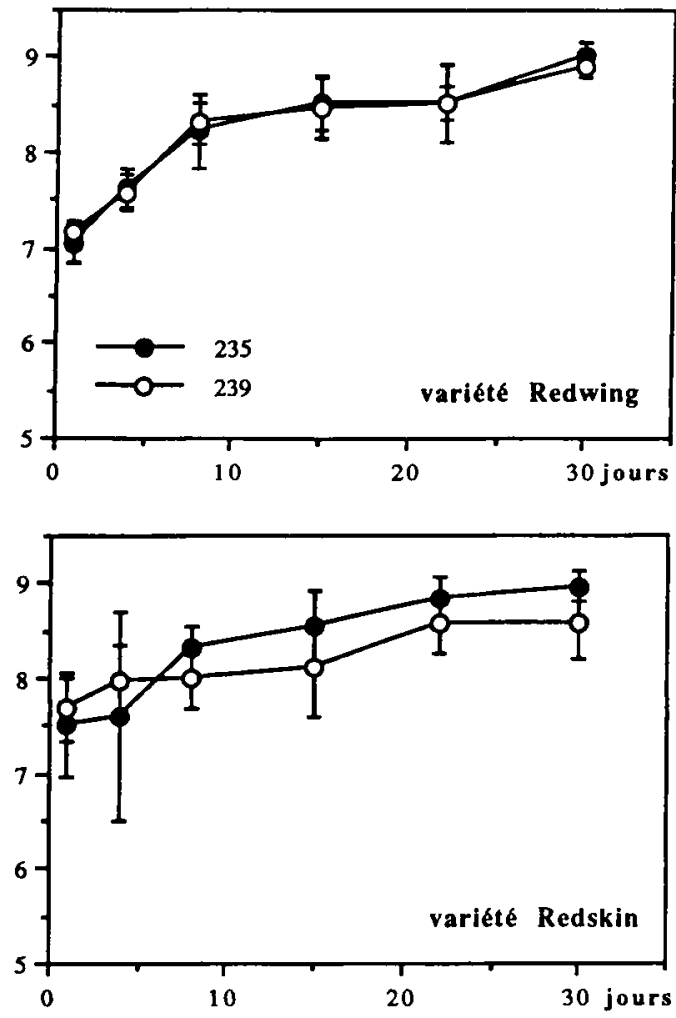

riche, donc en plein développement, doit être mis en parallèle avec ce qui peut être observé en verger; cette maladie ne se développe que durant le repos hivernal de l'arbre (Prunier et al, 1973) et l'inoculation pendant la période de végétation de toute souche, agressive ou non, conduit à la formation d'une nécrose de dimension limitée et non évolutive; un constat similaire a été fait par Crosse (1966) en ce qui concerne des souches du pathovar syringae inoculées à des arbres fruitiers en période d'activité végétative; la formation d'une nécrose limitée, atypique, peut être assimilée à une réaction de défense de la plante, de type hypersensibilité (Klement, 1963) ou non;

- sur vitroplant maintenu sur le même milieu pendant 20 semaines, on note des différences nettes de la dynamique des populations dans les tissus et d'intensité des symptômes. On peut supposer que le milieu de culture s'est appauvri en substances nutritives, ce qui a pu entraîner une modification de l'état physiologique des vitroplants et une réponse différenciée tant au niveau des dégâts que de la dynamique des populations bactériennes in vivo. On constate en effet une évolution spécifique de chaque clone bactérien, l'une caractéristique d'une infection consécutive à l'inoculation d'une souche agressive sur un hôte homologue, et l'autre s'apparentant plutôt à une réaction de défense consécutive à l'inoculation d'une souche non agressive ou défi-

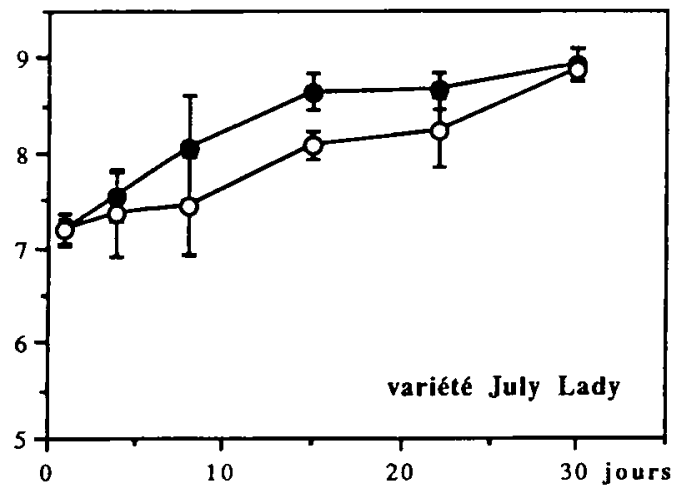

Fig 3. Dynamique de 2 clones de $P s$ pv persicae sur vitroplants de pêcher (essai 5) appartenant à 3 variétés différentes.

ciente. C'est aussi ce que constatent Hevesi et al (1978) après inoculation de $P$ fluorescens sur tabac.

L'appauvrissement du milieu peut conduire également à une acidification qui n'a pas été mesurée, ce qui pourrait être relié aux observations faites par Vigouroux et Huguet (1980) qui ont constaté que la sensibilité du pêcher à $P s$ pv persicae était accrue dans des sols acides et maigres.

- le vitroplant, maintenu sur un milieu en cours d'épuisement et soumis à différents traitements thermiques (choc thermique ou basse température associée à une photopériode inversée) réagit de manière différenciée à l'inoculation des 2 clones bactériens. Les dégâts apparaissent plus tôt et sont plus importants à $30 \mathrm{j}$ avec le clone 235 (nécrose totale du vitroplant au-dessus de la blessure) qu'avec le clone 239; l'intensité des dégâts est aussi plus élevée chez les vitroplants ayant subi un choc thermique; le clone 239 manifeste une difficulté d'installation dans le tissus; en revanche, le clone 235 se multiplie rapidement, dès le premier jour et nettement après le choc thermique ou l'installation en basse température; la dynamique du clone 239 dans les tissus, l'apparition de nécroses limitées mais certes significatives pour ce clone bactérien sont analogues aux observations faites sur pêcher par Luisetti (1983), pour qui ce type de réaction s'apparente à une réaction d'hypersensibilité. 
L'appauvrissement, le choc thermique et l'exposition à une température basse, séparément ou en association, entraînent un changement physiologique au niveau du vitroplant et une interaction différente avec la bactérie, ce qui se concrétise par des réponses différenciées au niveau des symptômes. Cette réponse du vitroplant est plus conforme à celle du pêcher en hiver.

Les essais réalisés sur vitroplants de pêcher conduisent à des conclusions voisines. Les observations faites sur le vitroplant de pêcher correspondent, au niveau des symptômes et pour les 2 clones bactériens, à celles faites sur vitroplant d'amandier $x$ pêcher conduit dans les mêmes conditions de température. Le choc thermique et le séjour à une température basse entraînent, pour les 3 variétés, Redwing, July Lady et Redskin, une réponse différenciée au niveau des symptômes avec un gradient entre les 3 variétés pour chacun des clones 235 et 239 . Un décalage dans l'apparition des symptômes entre les 3 variétés et entre les 2 clones bactériens est également mis en évidence. La dynamique dans les tissus n'est cependant pas différente entre les 2 clones bactériens. Ces résultats vont cependant dans le même sens que ceux observés en verger par Gardan et al (1971) qui ont classé ces 3 variétés dans les 3 catégories de sensibilité différente.

Pour analyser l'effet du choc thermique (exposition pendant $1 \mathrm{~h}$ à $-4{ }^{\circ} \mathrm{C}$ ), il est intéressant de comparer l'évolution des populations entre les essais 2 et 3 . Les niveaux de population atteints sur amandier $x$ pêcher avec le clone 235 sont, dans les 2 cas, identiques. En revanche, pour le clone 239 , les niveaux sont supérieurs, à 8 et à $15 \mathrm{j}$, pour les vitroplants d'amandier $\mathrm{x}$ pêcher ayant subi un choc thermique. Un niveau des populations plus élevé pour les plants ayant subi un choc thermique à $-4{ }^{\circ} \mathrm{C}$ persiste à $30 \mathrm{j}$. Deux hypothèses pourraient être émises sur l'action du froid. La première privilégierait une augmentation de la vitesse de multiplication in vivo, ce qui est vérifié pour le clone 239 dont le taux global de multiplication est nettement plus élevé sur des vitroplants ayant subi un choc thermique que sur ceux ayant subi tout autre traitement, mais non pour le clone 235 dont le taux de multiplication ne paraît pas être influencé par un traitement thermique. En revanche, pour un même niveau de population atteint après inoculation du clone 235, l'intensité des dégâts observés sur des vitroplants amandier $\mathrm{x}$ pêcher soumis à un refroidissement est significativement plus élevée. La se- conde hypothèse, d'une sensibilité plus grande des tissus, paraît donc plus probable. Sur les pêchers de la variété Redwing, inoculés avec le clone 235 et ayant subi un choc d' $1 \mathrm{~h}$ à $-3^{\circ} \mathrm{C}$, les dégâts apparaissent plus tôt et sont plus importants que sur les vitroplants de la même variété n'ayant pas subi de séjour à $-3^{\circ} \mathrm{C}$. Ces résultats sont comparables à ceux obtenus par Luisetti (1983) sur des arbres adultes en verger; il obtient en hiver des nécroses d'une longueur finale moyenne de $63 \mathrm{~mm}$ pour le clone 235 et de $12 \mathrm{~mm}$ pour le clone 239. Vigouroux (1974, 1979, 1989, 1991), a constaté sur pêcher que le refroidissement entraînait des modifications, tant physiques (congestion en eau des tissus) que biochimiques, favorables au développement de l'infection due à $P s$ pv persicae. Le même phénomène a été constaté avec $P s$ pv syringae sur pêcher (Weaver, 1978) et sur abricotier (Klement et al, 1974; Vigouroux, 1989). Des modifications de ce type pourraient favoriser la diffusion de la toxine du clone 235 et occasionner ainsi des dégâts importants. Cette interprétation rejoint celle de Williams et Keen (1967) qui soulignent le rôle du froid dans la diffusion de toxines bactériennes produits par $P s$ pv lachrymans sur concombre.

Une variabilité importante du niveau des populations apparaît dans certains des essais, et bien qu'il s'agisse d'une multiplication clonale tant pour le vitroplant que pour la bactérie, elle peut être due, soit à un effet plante, soit à un effet inoculation. Dans les deux cas il faudra prendre en compte cette variabilité dans la mise en place des dispositifs expérimentaux ultérieurs.

L'inoculation de 2 clones bactériens, l'un agressif et l'autre non agressif, sur 3 variétés appartenant aux 3 classes de sensibilité à $P s \mathrm{pv}$ persicae, a permis d'obtenir, sous certaines conditions de culture, des réponses différenciant aisément la variété peu sensible de la variété très sensible. En revanche, il apparaît difficile de situer les variétés de sensibilité intermédiaire. Du fait de la petite taille des vitroplants, une réponse intermédiaire obtenue avec une variété moyennement sensible est difficile à apprécier sur ce type de matériel. L'ensemble de ces résultats confirme que le vitroplant paraît être un bon outil pour trier à la fois le matériel microbiologique (agressif, non agressif) et le matériel végétal (très sensible et peu sensible).

II ne permet cependant de trier que les variétés et porte-greffes très sensibles et les variétés et porte-greffes peu sensibles à $P s \mathrm{pv}$ persicae, 
et est réservé aux seuls variétés et porte-greffes dont on maîtrise la culture in vitro. Il peut être utilisé comme test préliminaire à l'essai de plein champ. Un tel test permettrait de réaliser un tri précoce comme le suggère Dunez (1990) et serait particulièrement utile lors de l'arrivée sur le marché de nouvelles variétés de pêcher aux qualités agronomiques et de production intéressantes, et par là, promises à un développement rapide. Les améliorateurs de cette espèce fruitière ne prenant pas encore en compte dans leur programme de recherche la sensibilité à cette maladie, l'indication donnée par un test permettrait d'estimer le risque généré par une implantation massive de toute nouvelle variété, en particulier dans la région contaminée par cette bactérie. La non maîtrise de la multiplication in vitro de toutes les variétés de pêcher, et la difficulté d'obtenir des vitroplants avec des tiges bien développées constituent cependant une limite technique importante.

\section{CONCLUSION}

$\mathrm{Au}$ terme de cette série d'essais concernant l'étude du pouvoir pathogène de $P s$ pv persicae (souche agressive et souche non agressive) sur pêcher (ou hybride interspécifique amandier $x$ pêcher), le vitroplant apparaît comme un outil particulièrement intéressant. II réagit parfaitement aux conditions de milieu. On a pu simuler des situations de croissance active entraînant la résistance des tissus à des infections bactériennes (comme le pêcher en croissance) ou de traumatismes divers conduisant au développement de lésions (comme le pêcher pendant la période de repos végétatif). Ces résultats laissent augurer de l'utilisation du vitroplant de pêcher pour la poursuite d'études approfondies dans le domaine des relations hôte/parasite, ou dans le domaine de la sélection variétale. II présente par exemple, un intérêt certain pour mener des expérimentations avec des microorganismes génétiquement modifiés, tout risque de dissémination étant alors maîtrisé.

\section{REMERCIEMENTS}

Ce travail a été réalisé avec la collaboration du laboratoire de recherches de physiologie végétale d'Angers, qui a fourni les têtes de clones et le milieu de culture de l'amandier $x$ pêcher et avec l'aide d'Imad Dandal, étudiant, qui a participé aux travaux sur vitroplants de pêcher. Les auteurs remercient $M$ Bozzini pour la mise en forme de cet article.

\section{RÉFÉRENCES}

Boxus P, Quoirin M (1974) La culture de méristèmes apicaux de quelques espèces de Prunus. Bull Soc Roy Bot Belg 107, 91-101

Brisset MN, Paulin JP, Duron M (1988) Feasibility of rating fire blight susceptibility of pears (Pyrus communis) cultivars on in vitro microcuttings. Agronomie 8, 707-710

Carré M, Martin Tanguy J, Mussillon P, Martin C (1979) La culture de méristèmes et la multiplication végétative in vitro au service de la pépinière. Bull Petits Fruits 14, 8-65

Crosse JE (1966) Epidemiological relations of the pseudomonad pathogens of deciduous fruit trees. Annu Rev Phytopathol 4, 291-310

Dunez J (1990) Apport de la culture in vitro à la pathologie végétale. In: Les Colloques de I'INRA. Cinquantenaire de la culture in vitro $51,127-139$. INRA (ed) Versailles, Oct 1989

Flura D, Itier B, Brun O, Durand B, Masson S (1991) Mise au point de chambres de refroidissement pour l'étude de la gélivité des bourgeons. Application au cas de la vigne. Agronomie 11, 383-386

Gardan L, Luisetti J, Prunier JP (1971) Premiers résultats sur la sensibilité variétale du Pêcher au dépérissement bactérien (Pseudomonas morsprunorum f sp persicae). CR Acad Agric Fr séance 6/10/71, 1090/1094

Gardan L, Luisetti J, Prunier JP (1972) Variation in inoculum level of Pseudomonas morsprunorum persicae on leaf surface of peach trees. Proc 3rd Int Conf Plant Path Bact 87-94. Wageningen 1971

Hevesi M, Rivera N, Garcia A (1978) Pseudomonas fluorescens as pathogen on pepper plants. Proc 4th Int Conf Plant Path Bact 711-716. Angers 1978

Klement Z (1963) Rapid detection of the pathogenicity of phytopathogenic pseudomonads. Nature 199, 299-300

Klement Z, Rozsnyay S, Arsenijevic M (1974) II. Relationship of winter frost and the bacterial canker and dieback of apricots. Acta Phytopathol Acad Sci Hung 9, 35-45

Lopez MM, Navarro L (1981) A new in vitro inoculation method for Citrus canker diagnosis. Proc Int Soc Citriculture 1, 399-402

Luisetti J (1983) Quelques aspects de la variabilité de Pseudomonas persicae, agent du dépérissement bactérien du Pêcher. CR 3e Coll Rech Fruit 187200. Bordeaux 1983

Luisetti J, Gardan L, Prunier JP (1973) Études sur les bactérioses des arbres fruitiers. VI. Étude du pouvoir pathogène de $P$ mors-prunorum f sp persicae. 
Influence de la dose d'inoculum. Ann Phytopathol 5, 347-353

Luisetti J, Gaignard JL, Pacqueteau B, Lafuste JP (1984) Le dépérissement bactérien du Pêcher. Phytoma 358, 29-32

Luisetti J, Gaignard JL, Vigouroux A, Sanier R, Lafuste JP, Charras J (1992) Pêcher, dépérissement bactérien. Arbor Fruit 447, 19-28

Martin C (1980) La multiplication végétative in vitro: une technique de pointe au service de l'agriculture. CR Séance Acad Agric Fr 66, 629-637

Murashige T, Skoog F (1962) A revised medium for rapid growth and bioassays with tobacco tissue. Physiol Plant 15, 473-497

Navatel JC (1980) L'utilisation des cultures in vitro pour la multiplication de quelques espèces légumières et fruitières. CR Acad Agric Fr 66, 681-691

Navatel JC (1982) Problèmes liés à la production de porte-greffes d'arbres fruitiers pa la multiplication in vitro. Fruits 37, 331-336

Paulin JP, Luisetti J (1978) Ice nucleation activity among phytopathogenic bacteria. Proc 4th int Conf Plant Pathol Bact 725-731. Angers 1978

Prunier JP, Luisetti J, Gardan L (1970) Etudes sur les bactérioses des arbres fruitiers. II. Caractérisation d'un Pseudomonas non-fluorescent, agent d'une bactériose nouvelle du Pêcher. Ann Phytopathol 2, 181-197

Prunier JP, Luisetti J, Gardan L (1973) Études sur les bactérioses des arbres fruitiers. V. Étude du pouvoir pathogène de Pseudomonas mors-prunorum $\mathrm{f} \mathrm{sp}$ persicae, agent du dépérissement bactérien du pêcher. Méthodologie : premiers résultats sur l'influence de la date d'inoculation. Ann Phytopathol 5, 327-346

Vigouroux A (1968) Premières observations sur une nouvelle bactériose chez le Pêcher. $C R$ Séances Acad Agric Fr 54, 1021-1026
Vigouroux A (1970) Etudes sur les bactérioses des arbres fruitiers. A. Une nouvelle bactériose du Pêcher : description, étiologie, développement du parasite. Ann Phytopathol 2, 155-179

Vigouroux A (1974) Obtention de symptômes de bactériose du Pêcher (Pseudomonas morsprunorum $f$ $\mathrm{sp}$ persicae) sur rameaux de Pêcher détachés et conservés en survie. Effet du froid. Ann Phytopathol 6, 95-98

Vigouroux A (1979) Incidence des basses températures sur la sensibilité du Pêcher au dépérissement Bactérien. Ann Phytopathol 11, 231-239

Vigouroux A (1989) Ingress and spread of Pseudomonas in stems of peach and apricot promoted by frost-related water-soaking of tissues. Plant Dis 73 , 854-855

Vigouroux A (1991) Mechanism of cold-induced peach infection by Pseudomonas syringae pv persicae: water congestion in tissues. J Phytopathol 132, 139-145

Vigouroux A, Huguet C (1980) Prédisposition du Pêcher au dépérissement bactérien sur sols d'arène et de diluvion. Ann Phytopathol 12, 312

Vigouroux A, Berger F, Bussi C (1987) La sensibilité du pêcher au dépérissement bactérien en France : incidence de certaines caractéristiques du sol et de l'irrigation. Relations avec la nutrition. Agronomie 7 , 483-495

Weaver DJ (1978) Interaction of Pseudomonas syringae and freezing in bacterial canker on excised peach twigs. Phytopathology 68, 1460-1463

Williams PH, Keen NT (1967) Relations of cell permeability alteration to water congestion in cucumber angular leaf spot. Phytopathology 57, 13781385

Zuccherelli G (1979) Multiplicazione in vitro dei portainnesti clonali del pesco. Frutticoltura 9, 2, 15-20 